\title{
PROCESSO COMUNICACIONAL À LUZ DO ENEAGRAMA: ENSINO/APRENDIZAGEM ENTRE ESTAGIÁRIOS E DOCENTES DE ENFERMAGEM
}

\section{COMMUNICATION PROCESS IN THE LIGHT OF ENEAGRAMA: TEACHING/LEARNING BETWEEN NURSING TRAINEES AND TEACHERS}

\section{PROCEDIMIENTO COMUNICACIONAL A LA LUZ DEL ENEAGRAMA: ENSEÑANZA/APRENDIZAJE ENTRE ESTAGIARIOS Y DOCENTES DE ENFERMERÍA}

\author{
Denise Cristina Alves de Moura ${ }^{1}$, Cristina Arreguy-Sena ${ }^{2}$, Rosangela Maria Greco ${ }^{3}$, Zuleyce \\ Maria Lessa Pacheco ${ }^{4}$, Rúbia Mara Ribeiro ${ }^{5}$
}

Este artigo não recebe nenhum tipo de apoio financeiro.

O artigo é proveniente da disciplina Comunicação em Enfermagem: Possibilidades e Aproximações- desenvolvida no Programa de Pós-Graduação em Enfermagem da Universidade Federal de Juiz de Fora.

\begin{abstract}
RESUMO
Objetivo: Analisar o processo de ensino-aprendizagem entre professores supervisores e estagiários do Curso de Enfermagem na perspectiva do processo comunicacional de acordo com os tipos de personalidades segundo a técnica do Eneagrama. Métodos: Estudo de caso unitário entre estagiários e supervisores do curso de Enfermagem de uma universidade. Abordagem qualitativa, referencial teórico para análise: Eneagrama. Atendidas recomendações éticas de pesquisa envolvendo seres humanos. Resultados: Participaram dois docentes e oito discentes. As personalidades predominantes dos docentes foram perfeccionista e mediador e dos discentes perfeccionista, doador, desempenhador, romântico, contestador e mediador. Discussão: Na perspectiva do eneagrama, para o futuro enfermeiro trabalhar com pessoas com personalidade diferente lhe possibilita o autoconhecimento e a possibilidade de ajuda na relação docente/discente. Conclusões: Caracterizar as tendências comportamentais por meio do eneagrama constituiu uma estratégia para predizer a riqueza de oportunidades do processo ensino aprendizagem.
\end{abstract}

DESCRITORES: Enfermagem; Comunicação; Ensino; Aprendizagem; Personalidade.

\footnotetext{
${ }^{1}$ Enfermeira, Mestre em Enfermagem. Doutoranda em Saúde Coletiva. Universidade Federal de Juiz de Fora. Juiz de Fora-Minas Gerais - Brasil. E-mail: denisematipo@yahoo.com.br

${ }^{2}$ Enfermeira, Doutora em Enfermagem, Professora da Faculdade de Enfermagem da Universidade Federal de Juiz de Fora (FACENF/UFJF). Juiz de Fora - Minas Gerais - Brasil. E-mail: cristina.arreguy@ufjf.edu.br

${ }^{3}$ Enfermeira, Doutora em Saúde Pública, Professora FACENF/UFJF. Juiz de Fora - Minas Gerais - Brasil. E-mail: romagreco@gmail.com

${ }^{4}$ Enfermeira, Doutora em Enfermagem, Professora FACENF/UFJF. Juiz de Fora - Minas Gerais - Brasil. E-mail: zuleyce.lessa@ufjf.edu.br

${ }^{5}$ Enfermeira, Mestre em Enfermagem. Professora do Instituto Federal Sudeste de Minas Gerais. São João del Rei Minas Gerais - Brasil. E-mail: rm-ribeiro@ hotmail.com
} 


\begin{abstract}
Objective: To analyze the teaching-learning process between supervisors and trainees of the Nursing Course in the perspective of the communicational process according to the types of personalities according to the Enneagram technique. Methods: A unitary case study between trainees and supervisors of the Nursing course of a university. Qualitative approach, theoretical reference for analysis: Enneagram. Accomplished ethical research recommendations involving human beings. Results: Two teachers and eight students participated. The predominant personalities of the teachers were perfectionist and mediator and of the students perfectionist, donor, performer, romantic, answerer and mediator. Discussion: In the perspective of the enneagram, for the future nurse working with people with different personality allows him / her self-knowledge and the possibility of help in the teacher / student relationship. Conclusions: To characterize the behavioral tendencies through the enneagram was a strategy to predict the richness of opportunities in the teaching learning process.
\end{abstract}

DESCRIPTORS: Nursing; Communication; Teaching; Learning; Personality.

\title{
RESUMEN
}

Objetivo: Analizar el proceso de enseñanza-aprendizaje entre profesores supervisores y pasantes del Curso de Enfermería en la perspectiva del proceso comunicacional de acuerdo con los tipos de personalidades según la técnica del Eneagrama. Métodos: Estudio de caso unitario entre pasantes y supervisores del curso de Enfermería de una universidad. Enfoque cualitativo, referencial teórico para análisis: Eneagrama. A las recomendaciones éticas de la investigación que involucra a los seres humanos. Resultados: Participaron dos docentes y ocho alumnos. Las personalidades predominantes de los docentes fueron perfeccionista y mediador y de los discentes perfeccionista, donante, realizador, romántico, contestador y mediador. Discusión: En la perspectiva del eneagrama, para el futuro enfermero trabajar con personas con personalidad diferente le posibilita el autoconocimiento y la posibilidad de ayuda en la relación docente / discente. Conclusiones: caracterizar las tendencias comportamentales a través del eneagrama constituyó una estrategia para predecir la riqueza de oportunidades del proceso de enseñanza aprendizaje.

DESCRIPTORES: Enfermería; Comunicación; Enseñanza; Aprendizaje; Personalidad.

\section{INTRODUÇÃO}

As Diretrizes Curriculares

Nacionais (DCN) do Curso de Graduação

em Enfermagem estabelecem

competências e habilidades que devem se contempladas na formação do enfermeiro.

Entre as competências gerais a serem adquiridas pelos discentes de enfermagem em sua formação estão: a atenção à saúde; a tomada de decisões; a comunicação; a liderança, a administração e o gerenciamento e a educação permanente. ${ }^{1}$

Para alcançar a abrangência
prevista nas diretrizes e formar
enfermeiros generalistas, o curso de
Enfermagem deverá possuir um currículo
com diversidade de experiências, cenários,
situações clínicas, de investigação, de
gerência e de ensino com vistas a propiciar
aos discentes a aquisição de um perfil
crítico, reflexivo, embasado em princípios


científicos e éticos e com formação humanista. $^{1-2}$

$\mathrm{Na}$ profissão enfermagem, a finalidade do trabalho dos Enfermeiros é o cuidado e embora ele contemple cinco dimensões (investigar, assistir, gerenciar, ensinar e participar politicamente) $)^{3}$, um componente que perpassa todas estas dimensões é o processo comunicacional. Nesta perspectiva, a comunicação é concebida como a interação que sustenta o fazer, o pensar e o agir profissional, sendo o Enfermeiro e sua equipe emissores e receptores de mensagens para as quais a formação profissional privilegia a figura do Enfermeiro como o componente da equipe mais apto a captar, interpretar e responder as mensagens que recebe e transmite com a finalidade terapêutica. ${ }^{4-5}$

O cuidar é o encontro comunicativo entre quem cuida e quem é cuidado e, mesmo que tenha aparatos técnicos, envolve o contato humano. ${ }^{6}$ Como no processo comunicacional terapêutico as posições de receptor e emissor de mensagens são permutadas entre 0 Enfermeiro e o(s) usuário(s) numa relação dialógica intransferível e individualizada, o Enfermeiro deve ser capaz de captar mensagens comunicacionais que lhe forneça subsídios para tomar as decisões terapêuticas. Neste sentido a relação entre docente e discente durante sua formação acadêmica precisa desenvolver estas habilidades nos futuros enfermeiros, uma vez que o processo ensino/aprendizagem também pode ser analisado do ponto de vista comunicacional. $^{7}$

Estas habilidades precisam ser desenvolvidas desde a graduação para que o enfermeiro se conheça e adote comportamentos terapêuticos e não posicionamentos antiterapêuticos para que o exercício profissional se estabeleça independente de suas características pessoais. ${ }^{8}$ Para que este processo seja eficaz é necessário que a comunicação estabelecida esteja intrinsecamente ligada à forma como entendemos o outro. Como método de conhecimento do outro no que se refere à sua personalidade, elegemos como método de estudo o eneagrama.

O Eneagrama é uma expressão proveniente do grego que significa enneas (nove) e gramma (algo escrito), definido como um sistema de personalidade que identifica nove tipos distintos, a saber: perfeccionista; doador; desempenhador; romântico; observador; contestador; epicurista; chefe e mediador. Este método visa proporcionar autoconhecimento, descoberta das próprias potencialidades; crescimento autodirecionado; uma vida com mais equilíbrio e compreensão da própria personalidade. ${ }^{9}$

No entanto mesmo com um tipo de personalidade bem definida, os sentimentos e comportamentos podem 
alterar-se em situações de intenso estresse e em momentos de segurança. Isso não significa dizer que uma pessoa mudou de personalidade, mas que, nestas circunstâncias, assumirão características de outro tipo de personalidade. ${ }^{9}$

Outros fatores que podem interferir na explicação para formas diferentes de reação/posicionamento dentro de uma mesma personalidade inclui o nível de maturidade e as experiências adquiridas pelas pessoas ao longo de sua vida. Estas experiências formam esquemas que favorecem ou dificultam que comportamentos mal sucedidos sejam repetidos. As asas de derivação são outras modalidades de fatores intervenientes sobre a forma de expressão da personalidade dominante. Tais condições influenciarão a maneira como um indivíduo expressará seu tipo de personalidade. ${ }^{9}$

Cabe mencionar que a forma como uma pessoa se exprime em situações de estresse ou de segurança podem constituir em fatores intervenientes sobre o processo ensino/aprendizagem e sobre o processo de cuidar terapêutico.

Nas razões expostas a seguir se alicerçam a justificativa para a realização da presente pesquisa, a saber: o processo de cuidar é dialógico, ou seja, envolve a dimensão do profissional (Enfermeiro) e o indivíduo a ser cuidado (usuário). Ele Rev Enferm Atenção Saúde [Online]. Jan/Jul 2018; 7(1):129-142 ocorre a partir das peculiaridades de como o usuário percebe suas necessidades e de como as exprime; na relação entre Enfermeiro e usuário o processo comunicacional se constitui em estratégia relevante quando se pretende atingir o envolvimento de ambos em um objetivo comum, sendo o conteúdo emitido, a forma de veiculação deste conteúdo e a captação/recodificação por ambos, fundamentais para a convergência de esforços terapêuticos. Dessa forma, este estudo de abordagem qualitativa, foi desenvolvido com docentes e estagiários de enfermagem em seu cenário de prática, para compreender o processo ensinoaprendizagem considerando os tipos de personalidade e sua influência no processo comunicacional.

Assim, objetivou-se analisar o processo de ensino-aprendizagem entre professores supervisores e estagiários do Curso de Enfermagem na perspectiva do processo comunicacional de acordo com os tipos de personalidades segundo a técnica do Eneagrama.

\section{MÉTODOS}

Para o desenvolvimento deste estudo, utilizou-se uma abordagem qualitativa, delineada em estudo de caso unitário $^{10}$, com caráter descritivo e 
exploratório, adotando, a entrevista aberta como técnica de coleta de dados.

Como critério de elegibilidade para os discentes foram incluídos: todos aqueles: que cursaram o nono período do Curso de Graduação em Enfermagem da Faculdade de Enfermagem da Universidade Federal de Juiz de Fora (UFJF) no primeiro semestre letivo de 2012; de ambos os gêneros e com idade superior a 20 anos de idade; que concordaram em participar como voluntários não remunerados; que externaram sua aquiescência em participar pela assinatura do Termo de Consentimento Livre e Esclarecido após informação. Como critério de elegibilidade para os docentes foram considerados: aqueles que desenvolveram supervisão de estágio numa instituição de ensino público federal no primeiro semestre letivo de 2012; que concordaram em participar como voluntários não remunerados e que externaram sua aquiescência em participar pela assinatura do Termo de Consentimento Livre e Esclarecido após informação.

Foram considerados critérios de exclusão para os discentes: aqueles que realizaram estágio supervisionado em instituições não federais; aqueles que não atenderam aos critérios de inclusão; aqueles que mudaram de universidade ou estiveram de atestado ou afastamento no Rev Enferm Atenção Saúde [Online]. Jan/Jul 2018; 7(1):129-142 período de coleta de dados e os discentes cujo professor supervisor não aceitou participar da pesquisa. Para os docentes foram utilizados como critérios de exclusão: aqueles que não supervisionaram estágio no cenário onde os dados foram coletados; aqueles que não atenderam aos critérios de inclusão e aqueles que estiveram afastados ou de licença durante $o$ período de coleta de dados.

O cenário do estudo foi uma instituição de ensino público em nível federal de uma cidade de Minas Gerais e que possuía Curso de Graduação em Enfermagem operacionalizado em nove períodos letivos na ocasião em que os dados foram coletados.

O instrumento de coleta de dados foi estruturado de forma a: caracterizar os participantes, segundo dados demográficos; caracterizar os cenários de ensino/aprendizagem; captar as concepções de ensino e aprendizagem; classificar o tipo de personalidade dos participantes segundo o eneagrama, as tendências comportamentais e registrar impressões adicionais sobre a temática.

Os dados foram coletados nos meses de outubro, novembro e dezembro de 2012, com tempo médio de 30 minutos por entrevistas, sendo que as questões semiestruturadas tiveram duração média de 10 minutos. A coleta de dados ocorreu após aprovação do projeto no Comitê de 
Ética em Pesquisa sob o parecer de $n^{\circ}$ 107.344 de 2012.

Um questionário autopreenchido que continha questões de caracterização dos participantes e do processo ensino aprendizagem e uma entrevista contendo 180 questões acerca dos nove tipos de personalidades descritas pelo Eneagrama foi operacionalizado pela expressão verbal pausada e repetida por quantas vezes fizeram-se necessárias em entrevistas individuais não gravadas. Houve assessoramento das pesquisadoras para preenchimento dos impressos.

Conforme resolução 466/2012 ${ }^{11}$ os aspectos éticos e legais foram observados e garantidos, desde a submissão do projeto de pesquisa até a redação final do manuscrito.

\section{RESULTADOS}

Para atender aos objetivos da pesquisa, os dados coletados foram consolidados em planilha e cruzados aos pares (docente/discente) com a intenção de identificar pontos comuns ou divergentes, aproximações, afinidades e divergências por meio de análise qualitativa, tendo como referencial teórico para análise o Eneagrama.

Os binômios docentes/estagiários foram compostos por uma supervisora e cinco discentes e uma supervisora e três Rev Enferm Atenção Saúde [Online]. Jan/Jul 2018; 7(1):129-142 discentes, respectivamente, perfazendo dez participantes.

Os participantes foram predominantemente do gênero feminino, sendo que, sete pessoas estavam solteiras e três, casadas no momento da coleta de dados. Dentre as casadas cada uma possuía um filho. Entre as dez participantes, oito declararam ter cor de pele branca, uma parda e uma negra. A variação de idade das docentes foi de 43 e 50 anos e das discentes de 22 a 25 anos.

Dentre os locais/setores em que os discentes desenvolveram seu estágio estiveram presentes: setor de clínica, cirurgia, pediatria, Unidade de Terapia Intensiva, ambulatório e Unidade de Pronto Atendimento. Entre os participantes, nove disseram desenvolver atividades assistenciais; três, relataram desenvolver atividades gerenciais; três, de ensino e dois, de pesquisa.

O perfil do cenário e das atividades desenvolvidas foi caracterizado pelos sujeitos da pesquisa da seguinte forma: em relação ao nível de dependência, sete participantes classificaram a clientela do cenário onde seu estágio foi desenvolvido como parcialmente dependente; sete sujeitos relataram que a variabilidade de situações clínicas é média; seis participantes relataram que o contato com a família/acompanhante acontece muitas vezes e, seis sujeitos 
disseram que a rotatividade dos pacientes é media.

A avaliação da equipe de enfermagem pelos participantes ficou assim caracterizada: a receptividade foi considerada boa por cinco sujeitos e excelente por quatro; no que se refere ao envolvimento com o cuidado, cinco participantes o classificaram como bom e quatro como excelente; no que se refere à coesão para qualificar equipe de enfermagem seis sujeitos relataram que a equipe integrava grupo algumas vezes e o respeito e dedicação pelo usuário por parte da equipe de enfermagem foi relatado por seis participantes como sendo presente muitas vezes.

$\mathrm{Na}$ segunda parte do questionário foi realizada uma autoavaliação dos participantes em relação às competências e habilidades adquiridas e em construção (Quadro 1).

Quadro 1 - Autoavaliação de performance pelos estagiários de enfermagem: Competências e Habilidades. Juiz de Fora. Setembro/2017.

\begin{tabular}{|c|c|c|}
\hline $\begin{array}{l}\text { Competências } \\
\text { Habilidades }\end{array}$ & Adquirida & Em construção \\
\hline Comunicacionais & $\begin{array}{l}\text { boa- } 6 \text { participantes } \\
\text { excelente }-2 \text { participantes }\end{array}$ & $\begin{array}{l}\text { boa- } 2 \text { participantes } \\
\text { excelente }-2 \text { participantes }\end{array}$ \\
\hline Relacionais & $\begin{array}{l}\text { boa - } 7 \text { participantes } \\
\text { excelente - } 2 \text { participantes }\end{array}$ & boa - 2 participantes \\
\hline De Liderança & $\begin{array}{l}\text { boa - } 6 \text { participantes } \\
\text { ruim - } 1 \text { participante }\end{array}$ & boa - 7 participantes \\
\hline Gerencial/Administrativa & boa - 5 participantes & boa - 7 participantes \\
\hline Tomada de decisão & $\begin{array}{l}\text { boa - } 4 \text { participantes } \\
\text { excelente - } 1 \text { participante }\end{array}$ & boa - 7 participantes \\
\hline Assistencial & $\begin{array}{l}\text { boa }-5 \text { participantes } \\
\text { excelente }-2 \text { participantes }\end{array}$ & boa - 5 participantes \\
\hline Educação permanente & $\begin{array}{l}\text { boa - } 5 \text { participantes } \\
\text { excelente - } 1 \text { participante }\end{array}$ & boa - 7 participantes \\
\hline
\end{tabular}

Fonte: Dados do estudo, 2017.

Em relação ao tipo de ensino aprendizado vivenciado, cinco sujeitos relataram ter sido do tipo problematizador, quatro sujeitos disseram ser do tipo participativo e três bancário/transferência. As oportunidades de aprendizagem foram 
referidas por cinco sujeitos como sendo frequente e cinco sujeitos disseram que estas oportunidades acontecem sempre.

O último bloco do questionário abordou questões relativas aos sentimentos, sensações e comportamentos da adaptação no campo de estágio. Desta forma, oito pessoas disseram se sentir parcialmente seguras e decididas; seis sujeitos relataram sentimento de parcialmente útil/inserido no campo de estágio. Seis pessoas disseram que as oportunidades de aprendizado positivas são totalmente enriquecedoras; no entanto, as oportunidades negativas de aprendizado foram percebidas como sempre/frequente por três pessoas; muito frequente, por duas e pouco frequente por quatro pessoas.

Dentre as principais dificuldades listadas pelos estagiários e docentes tem-se: limitação do tempo, supervisão fragmentada, pouca receptividade da equipe, sobrecarga do último período letivo da graduação de enfermagem, medo do desconhecido, falta de habilidades práticas prévias, escassez de recursos materiais, problemas de relacionamento com a equipe, alta rotatividade de pacientes, dificuldade para assistir pacientes independentes, baixa autonomia dos enfermeiros, baixo preparo da equipe para receber e aceitar estagiários (exceto enfermeiros), falta de conhecimento teórico-prático dos estagiários, o fato do estágio ser em dupla, não trocar o cenário do estágio, desconfiança e horário do estágio.

No que se refere à caracterização da personalidade dos sujeitos de acordo com a técnica do Eneagrama, os resultados deste estudo demonstram que os docentes possuíam personalidades predominantes do tipo perfeccionista e mediador. Já os discentes tiveram as seguintes personalidades: perfeccionista, doador, desempenhador, romântico, contestador e mediador.

Não houve coincidência dos tipos de personalidades ou de comportamentos previstos de emergirem em situações de estresse e de estabilidade entre os binôminos analisados docente/discente (Quadro 2).

Quadro 2: Distribuição dos tipos de personalidades preponderantes entre os dez entrevistados, tendências em situações de estresse e segurança e asas de derivação. Juiz de Fora. Setembro/2017.

\begin{tabular}{|l|l|l|c|}
\hline \multirow{2}{*}{ Cenário } & $\begin{array}{c}\text { Tipo de Personalidade } \\
\text { Predominante }\end{array}$ & \multicolumn{2}{c|}{ Tendências Típicas } \\
\cline { 3 - 4 } & Tipo 1: Perfeccionista & Tipo 4: Romântico & Tipo 7: Epicurista \\
\hline Docente 1 & Tipo 3: Desempenhador & Tipo 9: Mediador & Tipo 6: Contestador \\
\hline Pediatria Estagiário 1 & Tipo & Tipo 4: Romântico \\
Clínica Mulher & Tipo 2: Doador & Tipo 8: Patrão & Tob segurança
\end{tabular}


Estagiário 2

\begin{tabular}{llll} 
Clínica Mulher & Tipo 9: Mediador & Tipo 6: Contestador & Tipo 3:Desempenhador \\
Estagiário 3 & & & \\
Clínica Homem & Tipo 3: Desempenhador & Tipo 9: Mediador & Tipo 6: Contestador \\
Estagiário 4 & & & Tipo 9: Mediador \\
Unidade de Terapia & Tipo 6: Contestador & Tipo 3: & \\
Intensiva & & Desempenhador & \\
Estagiário 5 & & Tipo 6: Contestador & Tipo 3:Desempenhador \\
Docente 2 & Tipo 9: Mediador & Tipo 9: Mediador & Tipo6: Contestador \\
\hline $\begin{array}{l}\text { Clinica/Cirurgia } \\
\text { Estagiário 1 }\end{array}$ & Tipo 3: Desempenhador & Tipod & \\
Unidade de Terapia & Tipo 4: Romântico & Tipo 2: Doador & Tipo 1:Perfeccionista \\
Intensiva Estagiário 2 & & & Tipo 7: Epicurista \\
Ambulatório & Tipo 1: Perfeccionista & Tipo 4: Romântico &
\end{tabular}

Fonte: Dados do estudo, 2017.

Dentre as habilidades relacionadas ao Eneagrama percebidas pelos participantes, três disseram ser o amor; três, o trabalho; duas a perfeição; duas, a liberdade; uma, a originalidade, uma, a verdade e uma, o conhecimento de tudo. Dentre as dificuldades listadas: oito pessoas relataram ter medo; cinco, ressentimento; três, dificuldade de planejamento; duas, preguiça; uma, tristeza; uma, raiva; uma, orgulho; e uma, falsidade. Dentre as qualidades, cinco disseram ser a humildade; três, a ação; três, a serenidade; duas, a honestidade; duas, a coragem e uma, a inocência.

Em relação à autopreservação, cinco sujeitos relataram a família; três, a ansiedade; um "dar conta" e um, a segurança. No que se refere à socialização, seis participantes referiram a participação; três, a amizade; dois, a vergonha; dois, a obrigação e um a inadaptação.

\section{DISCUSSÃO}

A maioria dos participantes considerou as competências e habilidades, acima descritas, como boa ou excelente, seja em construção ou adquirida, estando, portanto, em consonância com o que preconiza as Diretrizes Curriculares Nacionais (DCN) do Curso de Graduação em Enfermagem, que dispõe que tais competências e habilidades gerais devem ser contempladas na formação do enfermeiro. ${ }^{1}$ 
Alguns autores discutem que se as DCN do Curso de Graduação em Enfermagem forem adequadamente incorporadas à formação do enfermeiro, elas são capazes de gerar profissionais críticos reflexivos, com participação política, aptos a contribuírem para a resolução dos problemas de saúde da população e transformação da realidade. $^{12-13}$ Já no que diz respeito ao estágio curricular supervisionado, este possibilita a vivência de situações singulares de associação entre teoria e prática que serão imprescindíveis para a formação, qualificação e elaboração do perfil do futuro enfermeiro. $^{14}$

Quanto ao tipo de ensino aprendizado vivenciado, a maioria dos sujeitos relatou ser do tipo problematizador e a este respeito, a metodologia da problematização proposta por Paulo Freire considera os problemas como ponto de partida para o ensino e aprendizagem dos alunos, partindo da premissa que cada sujeito é composto de conhecimentos prévios que devem ser considerados no processo ensinoaprendizagem. Problematizar é considerado na perspectiva de promover autonomia dos indivíduos, o que se desenvolve a partir do diálogo, buscando a consciência crítica dos alunos. ${ }^{15-16}$ Portanto, o fato da maioria dos participantes vivenciarem esse tipo de ensino-aprendizagem mostra-se como fator positivo e enriquecedor para a formação dos mesmos, o que favorece também o processo comunicacional.

Em relação aos sentimentos, comportamentos da adaptação no campo de estágio e dificuldades elencadas pelos estagiários, a proposta dos currículos por competência, na área da saúde, prevê a inserção dos acadêmicos, ainda nos primeiros períodos dos cursos, em campos da prática profissional, possibilitando seu amadurecimento, desenvolvimento e segurança perante seu fazer cotidiano. Essa inserção precoce no campo de prática favorece maior articulação da teoria com a prática contribuindo para que os conhecimentos construídos sejam consolidados. $^{17}$

Neste estudo não houve coincidência dos tipos de personalidades entre os binôminos analisados docente/discente conforme a técnica do Eneagrama. Assim, vale destacar que a diversidade de perfil de personalidade convivendo, produz oportunidades para o desenvolvimento de habilidades e competências relacionais e comunicacionais que são fundamentais para a atuação do Enfermeiro em sua prática clínica e de ensino.

A seguir, estão descritas as características de cada tipo de personalidade segundo o Eneagrama. Tipo um perfeccionista: são pessoas que desejam que as coisas sejam sempre feitas de forma correta e que estas fiquem perfeitas. São 
pessoas altamente exigentes e organizadas, que conseguem localizar erros com facilidade. Tipo dois - doador: são pessoas prestativas e generosas que ficam satisfeitas quando se sentem uteis, no entanto às vezes não percebem as próprias necessidades. Tipo três - desempenhador: são indivíduos tarefeiros, competitivos, persistentes, gostam de enfrentar desafios e são considerados bons líderes. ${ }^{9}$

Tipo quatro - romântico: sentem que sua vida não está completa, são pessoas emotivas, dramáticas e solidárias. Tipo cinco - observador: são pessoas que mais observam que participam. São reservados, dão preferência a um tempo para si, gostam da rotina e levam uma vida organizada. Tipo seis - contestador: são pessoas que utilizam do pessimismo como forma de proteção, são medrosas, inseguras e desconfiadas, no entanto quando adquirem confiança são amigáveis. $^{9}$

Tipo sete - epicurista: são pessoas otimistas, com muita disposição, tem gosto por coisas e ideias novas, no entanto não gostam de ser enganadas. Tipo oito - chefe: são indivíduos extremistas, que lutam pelos seus ideais no que se refere à justiça e igualdade. Tendem a ser dominadores. Tipo nove - mediador: são pessoas que atuam para se atingir o equilíbrio entre duas partes de forma pacifica e conseguem entender o ponto de vista dos outros com facilidade. ${ }^{9}$
No presente estudo além de não haver coincidências de personalidades, também não houve coincidência de comportamentos previstos de emergirem em situações de estresse e de estabilidade. E a este respeito, torna-se importante refletir que na formação de futuros enfermeiros estratégias de autoconhecimento podem auxiliar os docentes a compreenderem como os discentes tendem a se comportar em situações de estresse e de segurança.

Esta compreensão mostra-se importante no processo de formação dos discentes, pois possibilita aos docentes criarem experiências exitosas no processo comunicacional e terapêutico e a identificação de modelos na prática clínica pode favorecer aos discentes a busca de habilidades e competências que não são natas em suas personalidades, sendo favorável que os docentes tenham empatia com os discentes e se instrumentalizem (técnica do eneagrama) a ponto de colaborarem com a autocompreensão de comportamentos de ambos quando vivenciam o processo ensino/aprendizagem e o cuidado de enfermagem.

Uma maneira de favorecer a aquisição da superação de reações estressantes durante o processo ensinoaprendizagem pode ser estimulada quando a concepção de educar adotada atribui ao professor o papel de facilitador deste processo. Para isto, ele precisa se conhecer e 
prever

reações/comportamentos/sentimentos dos educandos com vistas a intervir com êxito sobre sua formação, facilitando que o educando se conheça.

$\mathrm{Na}$ literatura pesquisada há uma escassez de estudos utilizando o Eneagrama, o que dificultou a comparação dos resultados encontrados nesta investigação com outras evidências científicas.

Em estudo desenvolvido na Korea também com estudantes de enfermagem, os resultados mostraram que o eneagrama foi muito eficaz no estabelecimento de autoidentificação positiva para os estudantes universitários de enfermagem que enfrentam crise de desenvolvimento e situações estressantes. $^{18}$

Outros dois estudos foram desenvolvidos na Korea com estudantes de medicina. Um deles avaliou a personalidade dos estudantes de medicina em relação ao estresse e nível de desenvolvimento utilizando o eneagrama. ${ }^{19} \mathrm{O}$ outro estudo mostrou uma experiência de utilização do eneagrama em um curso relacionado à motivação de calouros de medicina. ${ }^{20}$

$\mathrm{Na}$ perspectiva do eneagrama, o fato de trabalhar com pessoas com tipo de personalidade diferente lhe possibilita o autoconhecimento e a possibilidade de ajuda na relação docente/discente. $\mathrm{O}$ estudo de tendência de comportamentos em situações de crise/estresse favorece a utilização de Rev Enferm Atenção Saúde [Online]. Jan/Jul 2018; 7(1):129-142 técnicas de interação com vistas a se evitar confrontos, identificar possíveis alternativas de comportamentos para se evitar os problemas de comunicação.

\section{CONCLUSÕES}

Ao analisar o processo ensinoaprendizagem entre professores supervisores e estagiários do Curso de Graduação de Enfermagem na perspectiva do processo comunicacional segundo os tipos de personalidade da técnica do Eneagrama foi possível identificar que a diversidade de personalidades, de tendências de comportamentos em situações de estabilidade e de estresse constituiu numa variedade de oportunidades de auto e heterocrescimento.

Os binômios docentes/estagiários foram compostos por uma supervisora e cinco discentes e uma supervisora e três discentes, respectivamente, perfazendo dez participantes. Os docentes possuíam personalidades predominantes do tipo perfeccionista e mediador e os discentes: perfeccionista, doador, desempenhador, romântico, contestador e mediador, segundo a técnica do eneagrama. Não houve coincidência dos tipos de personalidades ou de comportamentos previstos de emergirem em situações de estresse e de estabilidade entre os binômios analisados. 
Como limitador desta pesquisa, pode-se considerar o fato de que os dados não podem ser extrapolados para a população em geral, uma vez que cada ser humano é único e, em cada processo comunicacional que se utiliza do eneagrama como ferramenta de autoconhecimento, novas análises devem ser aplicadas.

Assim, este estudo contribui para futuras pesquisas que pretendem prever conflitos e situações de enfrentamento dentro do processo de formação profissional que se utilizam do eneagrama como estratégia capaz de predizer a riqueza de oportunidades do processo ensino aprendizagem, e auto/heteroconhecimento dos participantes. Considerando o processo educacional e comunicacional como dimensões da atuação laboral de enfermeiros sugere-se a realização de outras investigações utilizando o eneagrama no processo ensino aprendizagem.

Conflito de interesses: Os autores declaram que não há conflito de interesses.

\section{REFERÊNCIAS}

1. Conselho Nacional de Educação, Câmara de Educação Superior (Brasil). Resolução $\mathrm{n}^{\circ}$ 3, de 7 de novembro de 2001. Institui Diretrizes Curriculares Nacionais do Curso de Graduação em Enfermagem [Internet]. D.O.U., Brasília, DF, 09 nov 2001 [citado em 15 maio 2016]. Disponível em: http://pesquisa.in.gov.br/imprensa/jsp/visuali $\mathrm{za} /$ index.jsp? jornal $=1 \&$ pagina $=37 \&$ data $=09 /$ $11 / 2001$

2. Meira MDD, Kurcgant P. O desenvolvimento de competências éticopolíticas segundo egressos de um curso de Graduação em Enfermagem. Rev Esc Enferm USP. [Internet]. 2013 [citado em 15 maio 2016]; 47(5):1211-8. Disponível em: http://www.scielo.br/pdf/reeusp/v47n5/pt_00 80-6234-reeusp-47-05-1203.pdf 3. Sanna MC. Os Processos de trabalho em enfermagem. Rev Bras Enferm. [Internet]. 2007 [citado em 15 maio 2016]; 60(2):221-

4. Disponível em: http://www.scielo.br/pdf/reben/v60n2/a17v6 0n2.pdf

4. Andrade CG, Costa SFG, Lopes MEM. Cuidados paliativos: a comunicação como estratégia de cuidado para o paciente em fase terminal. Ciênc Saúde Coletiva [Internet]. 2013 [citado em 23 mai 2016]; 18(9):2523$30 . \quad$ Disponível em: http://www.scielo.br/pdf/csc/v18n9/v18n9a0 6.pdf

5. Britto SMC, Ramos RS, Santos EI, Veloso OS, Silva AM, Mariz RGA.

Representação social dos enfermeiros sobre cuidados paliativos. Rev Cuid. [Internet]. 2015 [citado em 12 jun 2017]; 6(2):1062-9. Disponível em: http://www.scielo.org.co/pdf/cuid/v6n2/v6n2 a06.pdf

6. Pereira Teodoro AP, Figueiredo, MF. A comunicação em enfermagem e a argumentação retórica. Rev SELL. [Internet]. 2014 [citado em 12 jun 2017]; 4(1):1-21. Disponível em: http://seer.uftm.edu.br/revistaeletronica/ind ex.php/sell/article/viewFile/560/629

7. Amorim RKFCC, Silva MJP. Opinião de docentes de enfermagem sobre a efetividade da comunicação não verbal durante a aula. Acta Paul Enferm. [Internet]. 2014 [citado em 02 jun 2016]; 27(3):194-9. Disponível em:

http://www.scielo.br/pdf/ape/v27n3/19820194-ape-027-003-0194.pdf

8. Demandes I, Latrach CA, Febre NP, Muñoz C, Torres P, Retamal J. Evaluación 
del razonamiento científico y comunicación oral y escrita en el licenciado en enfermería. Rev Esc Enferm USP. [Internet]. 2012 [citado em 02 jun 2016]; 46(4):971-5. Disponível em: http://www.scielo.br/pdf/reeusp/v46n4/28.pd $\mathrm{f}$

9. Webb K. Fundamentos de eneagrama. 2ed. São Paulo: Avatar; 1998. 174p.

10. Yin RK. Estudo de caso: planejamento e métodos. 5ed. Porto Alegre: Boockman; 2015. 320p.

11. Conselho Nacional de Saúde (Brasil). Resolução n 466, de dezembro de 2012. Aprova as diretrizes e normas regulamentadoras de pesquisas envolvendo seres humanos. Brasília, DF: CONEP; 2013. 12. Silva MJ, Sousa EM, Freitas CL.

Formação em enfermagem: interface entre as diretrizes curriculares e os conteúdos de atenção básica. Rev Bras Enferm. [Internet]. 2011 [citado em 04 jul 2016]; 64(2):315-21. Disponível em:

http://www.scielo.br/pdf/reben/v64n2/a15v6 4n2.pdf

13. Teixeira E, Fernandes JD, Andrade AC, Silva KL, Rocha MEMO, Lima RJOL. Panorama dos cursos de graduação em enfermagem no Brasil na década das Diretrizes Curriculares Nacionais. Rev Bras Enferm. [Internet]. 2013 [citado em 04 jul 2016]; 66(Esp):102-10. Disponível em: http://www.scielo.br/pdf/reben/v66nspe/v66 nspea14.pdf

14. Souza DJ, Faria MF, Cardoso RJ, Contim D. Estágio curricular supervisionado sob a óptica dos enfermeiros supervisores. Rev Enferm Atenção Saúde [Internet]. 2017 [citado em 15 ago 2017]; 6(1):39-51.

Disponível em:

http://seer.uftm.edu.br/revistaeletronica/inde x.php/enfer/article/view/1677

15. Freire P. Pedagogia do oprimido. Rio de Janeiro: Paz e Terra; 2013.

16. Saul AM. Políticas e práticas educativas inspiradas no pensamento de Paulo Freire: pesquisando diferentes contextos. Currículo sem Fronteiras [Internet]. 2014 [citado em 23 jul 2016]; 14(3):129-42. Disponível em: http://www.curriculosemfronteiras.org/vol14 iss3articles/saul.pdf

17. Júnior MAF, Grígoli JAG, Ivo ML. Ensino por competências em enfermagem: interpretações e práticas pedagógicas. Rev Enferm Cent-Oeste Min. [Internet]. 2011 [citado em 23 jul 2016]; 1(2):143-53. Disponível em:

http://www.seer.ufsj.edu.br/index.php/reco $\mathrm{m} /$ article/view/81

18. Lee JS, Yoon JA, Do KJ. Effectiveness of Enneagram Group Counseling for selfidentification and depression in nursing college students. J Korean Acad

Nurs. [Internet]. 2013 [citado em 2017 Aug 15]; 43(5):649-57. Disponível em: https://www.jkan.or.kr/Synapse/Data/PDFD ata/0006JKAN/jkan-43-649.pdf 19. Hur Y, Lee K. Analysis of medical students' enneagram personality types, stress, and developmental level. Korean J Med Educ. [Internet]. 2011[citado em 2017 Aug 15]; 23(3):175-84. Disponível em: http://kjme.kr/upload/pdf/kjme-23-3-1754.pdf

20. Na BJ, Lee K, Kim K, Song D, Hur Y. Experience of developing and implementing a motivation induction course for Konyang University Medical College freshmen. Korean J Med Educ. [Internet]. 2012 [citado em 2017 Aug15]; 24(2):141-52. Disponível em: http://kjme.kr/upload/pdf/kjme-24-2141-7.pdf

RECEBIDO: $17 / 08 / 2017$

APROVADO: $18 / 06 / 2018$ PUBLICADO: 07/2018 